\title{
Soybean $\beta$-conglycinin Induces Intestinal Immune Responses in Chicks
}

http://dx.doi.org/10.1590/1806-9061-2018-0798

\section{-Author(s)}

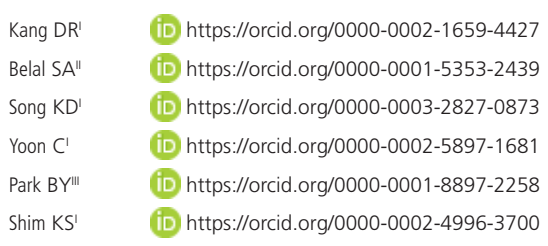

Department of Animal Biotechnology, College of Agriculture and Life Sciences, Chonbuk National University, Jeonju, Republic of Korea, 54896.

Department of Poultry Science, Sylhet Agricultural University, Sylhet-3100, Bangladesh.

III Department of Veterinary Embryology, College of Veterinary Science, Chonbuk National University, Iksan, Republic of Korea.

\section{nail Address}

Corresponding author e-mail address Kwan Seob Shim

Department of Animal Biotechnology, College of Agriculture and Life Sciences, Chonbuk National University, Jeonju, Jeollabukdo, Republic of Korea, 54896.

Phone: +82-01038891003

Email: ksshim@jbnu.ac.kr

\section{- Keywords}

$\beta$-conglycinin, mucosal immune response, cytokines, chick.

\section{ABSTRACT}

$\beta$-conglycinin from soybean has been recognized as one of the major feed allergens. This study investigated the effects of $\beta$-conglycinin-induced allergic sensitization on chicks' small intestines. A total of 407 -day-old $(100 \mathrm{~g})$ chicks were divided into four groups as control, $\beta$-conglycinin 1 $\mathrm{h}, \beta$-conglycinin $6 \mathrm{~h}$, and $\beta$-conglycinin $12 \mathrm{~h}$. All treatment groups were administered $60 \mathrm{mg}$ of $\beta$-conglycinin/chick and small intestine samples were collected. $\beta$-conglycinin-induced allergic sensitization marginally damages the epithelium lining of the duodenum villi and, in addition, significantly increases the accumulation of mast cells in the lamina propria and crypt of the duodenum. Moreover, the TNF- $\alpha$ level significantly increased in all $\beta$-conglycinin groups. IL-8 and IL-2 were significantly downregulated in the $1 \mathrm{~h}$ group; however, there were increases for the 6 $\mathrm{h}$ and $12 \mathrm{~h}$ groups. These results suggest that $\beta$-conglycinin may lead to an inflammatory response in the chicks' small intestines.

\section{INTRODUCTION}

Soybean, a member of the legume's family, is a good protein source because of a high protein composition (37-42\%) with a rich and good balance of amino acids as well as a nutritional and healthy food (Radder \& Husen 2017). However, they have a high content of storage proteins that inhibit their nutrient function and can also cause inflammation and allergic reactions (Boehm et al. 2017). It reduces the nutritional value of soybeans. Most storage proteins consist of globulin (70\%), the main components being $\beta$-conglycinin (7S) and glycinin (11S) $\mathrm{Wu}$ et al. 2017). These are known as allergy-causing proteins in soybeans. $\beta$-conglycinin and glycinin were administered to animals and it was discovered that the former had a greater influence on the immune response of the small intestine (Zhao et al. 2008). There have been many attempts to extract $\beta$-conglycinin from soybeans and to feed rodents, pigs and fishes. In the experiments feeding the purified $\beta$-conglycinin from soybean, it reduced animal growth and increased feed requirement (Zhao et al. 2008), histamine and IgE levels (Hao et al. 2009), induced passive cutaneous anaphylaxis, upregulated CD4+ lymphocyte ratio, and increased cytokine concentrations of plasma and spleen (Guo et al. 2007). Based on these results, $\beta$-conglycinin stimulated the immune response and induced an allergic reaction through the digestive tract.

However, studies on chickens are very rare and the fact that chickens have very different digestive organs, compared to other monogastric animals, this provides a good reason for more research.

In this study, isolated $\beta$-conglycinin from soybean was confirmed by SDS-PAGE and $\beta$-conglycinin was treated to chicks. Afterwards, the small intestine's histology and mRNA expression which affect the mechanisms of inflammatory reactions on chicks were analysed. 


\section{MATERIALS AND METHODS}

\section{Isolation of $\beta$-conglycinin and glycinin}

Soybean was purchased from an agricultural cooperative of Soyang in Korea. Soybean flour (60 mesh) was defatted with hexane $(1: 8, w / v$, soybean flour/hexane). The $\beta$-conglycinin (7S) and glycinin (11S) were isolated according to the modified method of Thanh et al. (1975).

\section{SDS-PAGE (Sodium dodecyl sulfate- polyacrylamide gel electrophoresis)}

SDS-PAGEwasperformed withwholesoybean protein (WSB), $\beta$-conglycinin, and glycinin for comparison and confirmation. The protein concentration of soybean fractions was determined with the DC protein assay kit (Biorad, USA) using bovine serum albumin as a standard, following the manufacturer's instructions. Electrophoresis of soybean fractions was performed by $12 \%$ acrylamide (the acrylamide/bis-acrylamide ratio was 29:1) using Mini-Protein tetra cell (Biorad, USA). Protein separation was carried out at $20 \mathrm{~mA}$. Afterwards, the gels were stained using Coomassie blue $\mathrm{R}-250$ ( $\mathrm{R}$ = reddish hue) and scanned by Bio-5000 plus (Microtec Co.).

\section{Experimental animals}

A total of 40 7-day-old broiler chicks with an average weight of $100 \mathrm{~g}$ were used in this experiment. Ten chicks per group were randomly allocated: the control group (C) caught first; those caught $1 \mathrm{~h}$ after administration (1 h); $6 \mathrm{~h}$ after administration ( $6 \mathrm{~h}$ ); $12 \mathrm{~h}$ after administration (12 h). $\beta$-conglycinin that was isolated from soybean for oral administration was prepared in phosphate buffered saline (PBS) (60 $\mathrm{mg} \beta$-conglycinin/100 $\mu \mathrm{l} \mathrm{PBS} /$ chick). After $24 \mathrm{~h}$ of fasting, ten chicks from the control group (C) were administered with only PBS, and the other thirty chicks of $\beta$-conglycinin treatment groups $(1 \mathrm{~h}, 6 \mathrm{~h}$ and $12 \mathrm{~h}$ groups) were administered $\beta$-conglycinin. All chicks received water ad libitum. Then randomly six chicks were selected for liver sample per treatment group. Small intestine samples were collected and separated into two types: one was put into 10\% neutral buffered formalin (NBF) for histology and the other was immediately put into liquid nitrogen for qRT-PCR.

\section{Histological analysis}

The small intestine (duodenum) of the experimental chick was excised for histopathological examination. Samples were immediately fixed in 10\% neutral buffer formalin (NBF). After $24 \mathrm{~h}$ fixation, the samples were trimmed and processed using an auto processor (Excelsior ES, Thermo Scientific, USA) and embedded in paraffin wax. Sections of $5 \mu \mathrm{m}$ duodenum tissue were stained with hematoxylin and eosin (H\&E) and mounted on a glass slide. Digital images were picked up using a Leica DM2500 microscope (Leica Microsystems, Germany) at fixed $100 \times$ magnifications.

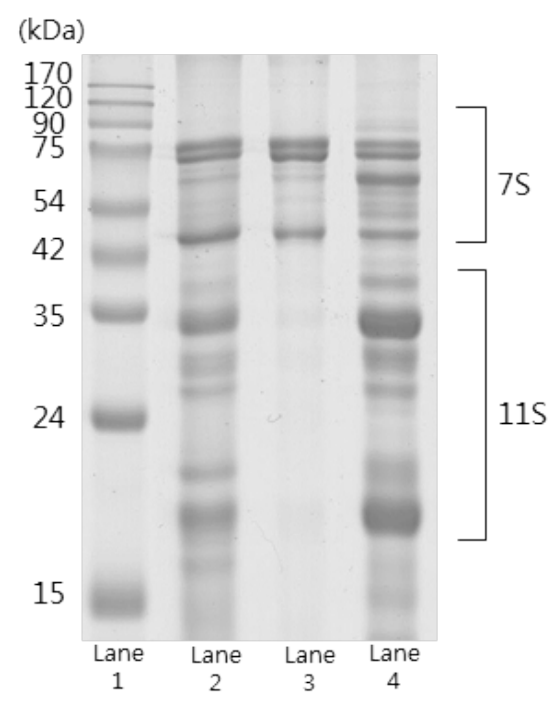

Figure 1 -SDS-PAGE of glycinin and $\beta$-conglycinin from soybean. Lane 1: marker, Lane2: whole soybean, Lane3: $\beta$-conglycinin soybean, Lane4: glycinin from soybean.

\section{Mast cell counting}

The duodenum of experimental chicks was excised and immediately fixed in $10 \%$ NBF. After $24 \mathrm{~h}$ fixation, the samples were trimmed and processed by using the auto processor (Excelsior ES, Thermo Scientific, USA) and embedded in paraffin wax. 5 um sections of intestinal tissue were stained with toluidine blue $(0.1 \%)$ for identification of mast cells and mounted on a glass slide. Digital images were picked up using Leica DM2500 microscope (Leica Microsystems, Germany) at fixed $100 \times$ magnifications. The number of total mast cells (violet color/red purple color) was counted manually.

\section{qRT-PCR}

Total RNA was extracted from the duodenum using the AccuZol total RNA extraction reagent (Bioneer, Korea) according to the manufacturer's manual; quality and concentration of extracted RNA were determined with a microplate reader (NanoDrop, Thermo Fisher). cDNA was synthesized with AccuPower Cycle Script RT Premix (dT20) (Bioneer, Korea). Primer sequences are shown in Table 1. All primers were designed by the Primer 3 (v. 0.4.0) software and synthesized by Bioneer Corporation (Bioneer, Korea). The realtime $\mathrm{qPCR}$ 
Kang DR, Belal SA, Song KD, Yoon C, Park BY, Shim KS

\section{Soybean $\beta$-conglycinin Induces Intestinal Immune Responses in Chicks}

mixture was prepared using SYBR green fluorescence (SsoFast ${ }^{\mathrm{TM}}$ EvaGreen ${ }^{\circledR}$ Supermix, Biorad, USA) and quantification was performed by CFX96 ${ }^{\mathrm{TM}}$ Real-Time PCR detection system (Biorad, USA) following the manufacturer's protocol. Every gene expression was analyzed and normalized using GAPDH (reference gene) with a duplicate.

Table 1 - Composition of basal diets.

\begin{tabular}{lc}
\hline Items & Composition \\
\hline Ingredients, g/kg & \\
Corn & 504.3 \\
Corn gluten meal & 35.0 \\
Soybean meal & 357.2 \\
Soybean oil & 60.0 \\
\hline DCP & 18.6 \\
Limstone & 15.4 \\
99\%-Methionine & 1.5 \\
Salt & 2.0 \\
Vitamin-mineral premix & 5.0 \\
Sodium bicarbonate & 1.0 \\
\hline Total & 1000 \\
Nutrients* & \\
\hline Metabolisable energy, kcal/kg & 3113.56 \\
Crude protein, \% & 23 \\
Lys & 1.19 \\
\hline Met+Cys & 0.85 \\
\hline Met & 0.50 \\
Ca & 1.00 \\
\hline Available phosphorus & 0.45 \\
\hline
\end{tabular}

${ }^{*}$ Calculated value based on the analysed data of experimental diets.

\section{Statistical analysis}

The results were presented as means \pm standard error (SE). All data were analyzed using an ANOVA (analysis of variance) procedure with the SAS software version 9.4 (SAS institute Inc.). Statistical significance was indicated at $p<0.05$, based on Duncan's Multiple Range Test. TNF- $\alpha$, IL-8, IL-2, and IL-1 were statistically evaluated by Student's t-test for unpaired comparisons.

\section{RESULTS AND DISCUSSION}

\section{$\beta$-conglycinin and glycinin isolation}

In this experiment, a method for isolating and purifying soybean insoluble proteins, $\beta$-conglycinin and glycinin, was constructed for the specification experiment using the insoluble protein $\beta$-conglycinin. The proteins were separated by SDS-PAGE, and the positions of the same proteins were compared and confirmed by previous studies (Wang et al. 2014, Yamada et al. 2014, Perrechil et al. 2015). Compared with previous studies, $\beta$-conglycinin was well separated, but the glycinin was not separated purely.

\section{Modification of duodenum histology of chicks sensitized with $\boldsymbol{\beta}$-conglycinin}

To evaluate the effects of $\beta$-conglycinin on the small intestine of chicks after oral administration, modifications of the duodenum's histological structure were observed and revealed that they were marginal in experimental chicks compared to the control group (Figure 2). We found that the epithelium lining of the duodenum tips' villi was slightly damaged by $\beta$-conglycinin-induced allergic sensitization. $\beta$-conglycinin is the key storage protein of soybeans which is a prospective diagnostic indicator for allergic reactions to soy (Wu et al. 2016, Ashaolu \& Yupanqui 2017). Evidence showed that histological damages of small intestines are a common feature in animal oral gavages of soybean allergens (Liu et al. 2008, Zhang et al. 2013). B-conglycinin originating from undigested soybean meal may cause damage of the intestinal epithelial mucosa and concurrently disturb nutrient absorption (Dunsford et al. 1989). Serum immunoglobulins (IgE and IgG1) were associated with the allergic sensitization of chicks. These antibodies stimulated the intestinal mast cells' degranulation and caused releases of elevated plasma histamine that leads to intestinal damages and contributes to systemic anaphylaxis (Kumar Gupta et al. 2016, Taketomi et al. 2017).

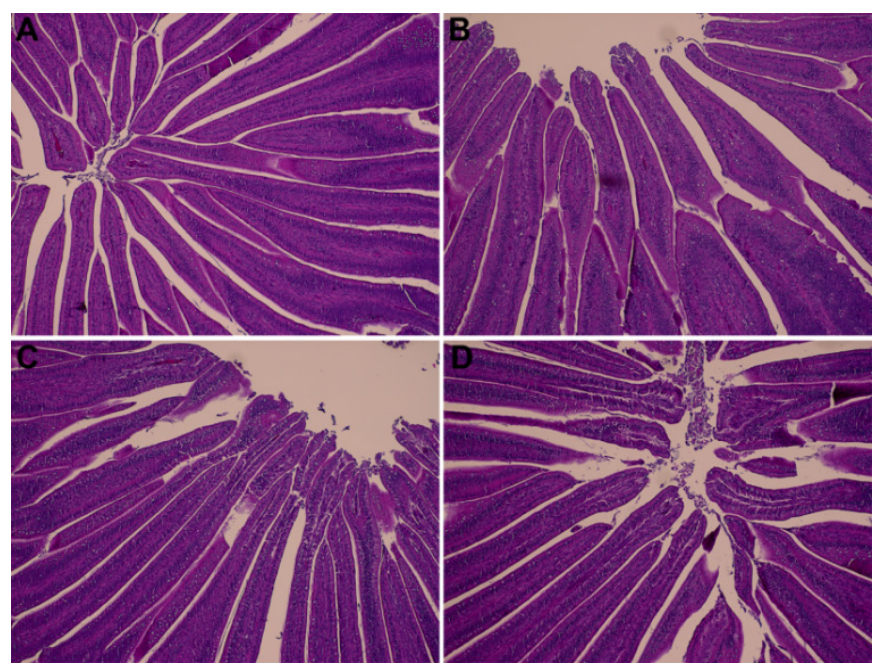

Figure 2 - $\beta$-conglycinin prompts damages to the duodenum's histological structure in experimental chicks (A. control, B. 1 h, C. 6 h, and D. 12 h).

\section{$\beta$-conglycinin provokes the mast cell number in the duodenum}

Mast cell number in the small intestine is an important marker of allergic sensitization (Hao et al. 2010). The activates and inactivates of mast cells and histamine are closely linked and we can divide them into two processes. First, the mast cell is activated by the antigen-specific IgE and release hiatamine. Second, 
Table 2 - Real time quantitative primer sequences.

\begin{tabular}{|c|c|c|c|}
\hline Gene name & Product size (bp) & strand & Sequence $\left(5^{\prime}-3^{\prime}\right)$ \\
\hline \multirow{2}{*}{ TNF- $\alpha$} & \multirow{2}{*}{395} & Sense & AGA TGG GAA GGG AAT GAA CC \\
\hline & & antisense & ACT GGG CGG TCA TAG AAC AG \\
\hline \multirow{2}{*}{ IL-8 } & \multirow{2}{*}{371} & Sense & GCT CTG TCG CAA GGT AGG AC \\
\hline & & antisense & GCG TCA GCT TCA CAT CTT GA \\
\hline \multirow{2}{*}{ IL-2 } & \multirow{2}{*}{212} & Sense & ACC GGA AGT GAA TGC AAG AT \\
\hline & & antisense & AGT GGT CCC AGA ATG GAC AG \\
\hline \multirow{2}{*}{ IL-1 } & \multirow{2}{*}{263} & Sense & GCA TCA AGG GCT ACA AGC TC \\
\hline & & antisense & CAG GCG GTA GAA GAT GAA GC \\
\hline \multirow{2}{*}{ GAPDH } & \multirow{2}{*}{133} & Sense & AGA ACA TCA TCC CAG CGT CC \\
\hline & & antisense & CGG CAG GTC AGG TCA ACA AC \\
\hline
\end{tabular}

the released histamine concentration causes the mast cell to degranulation and secrete cytokines (Guo et al. 2008). Therefore, we determined their total number in the duodenum. A number of mast cells markedly increased at $6 \mathrm{~h}$ and $12 \mathrm{~h}$ in the $\beta$-conglycinin treated group as compared to the control (Figure 3). According to our results, upregulated mast cells can release histamines. The intestinal damages allow antigens to pass first into the systemic circulation, prompting the release of specific cytokines. Evidence exists that histamine levels in $\beta$-conglycinin-sensitized animals were significantly elevated as a result of mast cell accumulation in the small intestine (Liu et al. 2008, Sun et al. 2008). Consistent with such reports, we found an increased number of mast cell accumulations in the chicks' duodenum after $\beta$-conglycinin administration. However, (Liu et al. 2008) showed that the mast cell from BALB/C mice significantly decreased after 14 days after sensitized by $\beta$-conglycinin, caused by histamine release. It can be inferred that this is the result of the second processing by histamine.

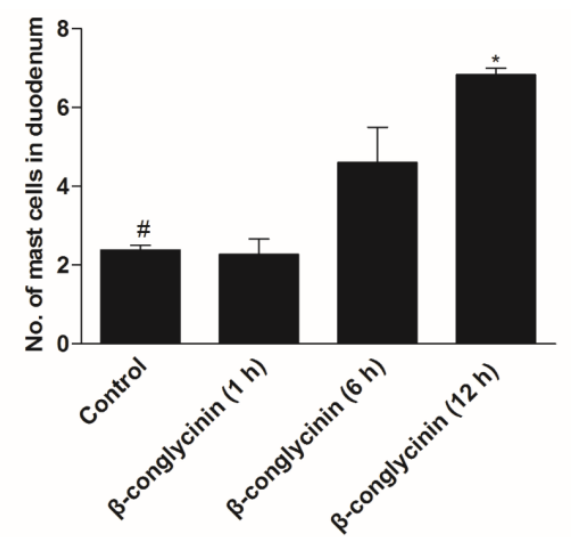

Figure 3 - Quantification of duodenum mast cells in $\beta$-conglycinin-treated chicks. ${ }^{*, *}$ : Columns with different superscripts differ $(p<0.05)$.

\section{TNF-a, IL-8, IL-2, and IL-1 expression by} $\beta$-conglycinin

To investigate the effect of $\beta$-conglycinin on chicks, inflammation-related cytokines such as TNF- $\alpha, \|-8$, II-
2, and II-1 genes were analyzed by qRT-PCR (Figure 4). TNF- $\alpha, I L-8$, IL-2 and IL-1 are cytokines, small proteins, that mediate inflammatory responses and that activate macrophages and releases by cells to send signals to other cells and are indicators to pro-inflammatory. TNF- $\alpha$ is related to allergies and asthma induction (Nguyen et al. 2016). The level at which TNF- $\alpha$ increased depended on time. This result indicated that inflammation occurred in the small intestine. Increased IL-8 levels were found in patients' inflammatory areas and associated with cancer, acute myeloid leukemia, chronic obstructive pulmonary disease, and asthma (Beigelman et al. 2015). The levels of IL-8 and IL-2 decreased at the beginning of the $\beta$-conglycinin administration. However, depending on time, an increment of the IL-8 and IL-2 levels showed allergic and inflammatory reactions. However, over time, the IL-1 levels decreased significantly, and its expression diminished consistently.
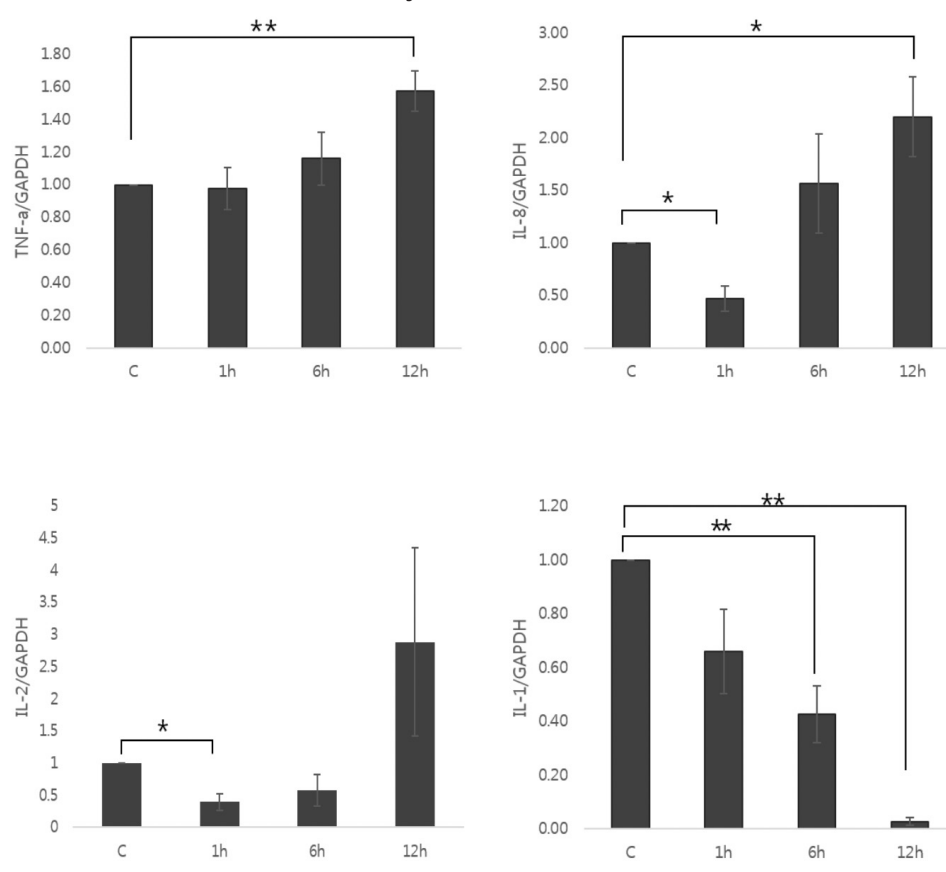

Figure 4 - Expression of TNF- $\alpha$, IL-8, IL-2, and IL-1 mRNA levels in the intestines of $\beta$-conglycinin treated chicks. 
Many studies have examined the genes involved in the immune response after feeding the animals with extracted or purified $\beta$-conglycinin. Various animal species were analyzed such as fish, rodents, pigs and others. According to (Zhang et al. 2013), TNF-a significantly increased in the intestine after feeding $\beta$-conglycinin to the fish, and IL-8 and IL-1 decreased. In addition, TNF-a and IL-1 significantly increased in juvenile turbot (Li et al. 2017) and Mitten crab (Han et al. 2019) contained in fish species. In mouse epithelia cell treated with $\beta$-conglycinin, IL-8, IL-6, and IL-2 significantly increased (Xu et al. 2010), and in other experiments using rats, IL-2 decreased and IL-4, IL-5 and TNF- $\alpha$ increased (Guo et al. 2007). Overall, in the results from the published papers, $\beta$-conglycinin-fed animals showed negative effects on the intestine, which is consistent with this study. However, depending on the species and experimental type (in vivo or in vitro), the expression patterns of immune responsive genes or factors were different.

In conclusion, we analyzed $\beta$-conglycinininduced allergic reactions in chicks' small intestines. $\beta$-conglycinin was isolated from soybean flour and analyzed by SDS-PAGE. A total of 24 chicks were divided into four groups such as control, $\beta$-conglycinin $1 \mathrm{~h}, \beta$-conglycinin $6 \mathrm{~h}, \beta$-conglycinin $12 \mathrm{~h}$ - and the small intestine was analyzed. In the histology analysis, we observed that the $\beta$-conglycinin-induced allergic sensitization groups' duodenum villi epithelia were slightly damaged depending on time. Also, mast cell numbers significantly increased in $\beta$-conglycininsensitized groups within the duodenal lamina propria and crypt. Moreover, the mRNA expression of TNF- $\alpha$, $\mathrm{IL}-8$, and IL-2 increased in $\beta$-conglycinin treatment depending on the sensitization time. These results indicate that $\beta$-conglycinin may lead to immune responses by allergic sensitization in small intestines of chicks.

\section{ACKNOWLEDGEMENTS}

This research was supported by a grant from the Next-Generation BioGreen 21 Program (Project No. PJ011831), Rural Development Administration, Republic of Korea.

\section{REFERENCES}

Ashaolu TJ, Yupanqui CT. Suppressive activity of enzymatically-educed soy protein hydrolysates on degranulation in IgE-antigen complexstimulated RBL-2H3 cells. Functional Foods in Health and Disease 2017;7(7):545-561.
Beigelman A, Isaacson-Schmid M, Sajol G, Baty J, Rodriguez OM, Leege $\mathrm{E}$, et al. Randomized trial to evaluate azithromycin's effects on serum and upper airway IL-8 levels and recurrent wheezing in infants with respiratory syncytial virus bronchiolitis. Journal of Allergy and Clinical Immunology 2015;135(5):1171-1178.

Boehm JD, Nguyen V, Tashiro RM, Anderson D, Shi C, Wu X, et al. Genetic mapping and validation of the loci controlling 7S $\alpha^{\prime}$ and 11S A-type storage protein subunits in soybean [Glycine max (L.) Merr.]. Theoretical and Applied Genetics 2017;1-13.

Dunsford BR, Knabe D, Haensly W. Effect of dietary soybean meal on the microscopic anatomy of the small intestine in the early-weaned pig. Journal of Animal Science 67(7):1855-1863,1989.

Guo P, Piao X, Cao Y, Ou D, Li D. Recombinant soybean protein $\beta$-conglycinin $\alpha$-subunit expression and induced hypersensitivity reaction in rats. International Archives of Allergy and Immunology 2008;145:102-110.

Guo P, Piao X, Ou D, Li D, Hao Y. Characterization of the antigenic specificity of soybean protein $\beta$-conglycinin and its effects on growth and immune function in rats. Archives of Animal Nutrition 61:189-200,2007.

Han F, Wang X, Guo J, Qi C, Xu C, Luo Y, et al. Effects of glycinin and $\beta$ conglycinin on growth performance and intestinal health in juvenile Chines mitten crabs (Eriocheir sinensis). Fish \& Shellfish Immunology 2019;84:269-279

Hao $Y$, Li D, Piao $X$, Piao $X$. Forsythia suspensa extract alleviates hypersensitivity induced by soybean $\beta$-conglycinin in weaned piglets. Journal of Ethnopharmacology 128(2):412-418, 2010.

Hao Y, Zhan Z, Guo P, Piao X, Li D. Soybean $\beta$-conglycinin-induced gut hypersensitivity reaction in a piglet model. Archives of Animal Nutrition 2009;63:188-202

Kumar Gupta R, Kumar S, Gupta K, Sharma A, Roy R, et al. Cutaneous exposure to clinically-relevant pigeon pea (Cajanus cajan) proteins promote TH2-dependent sensitization and IgE-mediated anaphylaxis in Balb/c mice. Journal of Immunotoxicology 2016;13(6):827-841.

Li Y, Hu H, Liu J, Yamg P, Zhang Y, Ai Q, et al. Dietary soya allergen $\beta$ conglycinin induces intestinal inflammatory reactions, serum-specific antibody response and growth reduction in a carnivorous fish species, turbot Scophathalmus maximus L. Aquaculture Research 2017;48:4022-4037.

Liu X, Feng J, Xu Z, Wang Y, Liu J. Oral allergy syndrome and anaphylactic reactions in $B A L B / C$ mice caused by soybean glycinin and $\beta$-conglycinin. Clinical \& Experimental Allergy 2008;38(2):350-356.

Nguyen TH, Maltby S, Simpson JL, Eyers F, Baines KJ, Gibson PG, et al. TNF- $\alpha$ and Macrophages are critical for respiratory syncytial virusinduced exacerbations in a mouse model of allergic airways disease. The Journal of Immunology 2016;196(9):3547-3558.

Perrechil F, Ramos V, Cunha R. Synergistic functionality of soybean 7s and $11 \mathrm{~s}$ fractions in oil-in-water emulsions: effect of protein heat treatment. International Journal of Food Properties 2015;18(11):2593-2602.

Quan TE, Cowper S, Wu SP, Bockenstedt LK, Bucala R. Circulating fibrocytes: collagen-secreting cells of the peripheral blood. The International Journal of Biochemistry \& Cell Biology 2004;36(4):598-606.

Radder B, Husen S. Effect of iron sulfate application on yield, nutrient uptake and available nutrient status of soybean at harvest (Glycine max L.) in Vertisols of Karnataka, India. Environment and Ecology 2017;35(2C):1336-1340

Sun P, Li D, Li Z, Dong B, Wang F. Effects of glycinin on IgE-mediated increase of mast cell numbers and histamine release in the small intestine. The Journal of Nutritional Biochemistry 2008;19(9):627-633. 
Taketomi EA, Miranda JS, Cunha-Júnior JP da, Oliveira Silva DA de. Allergenspecific immunotherapy follow-up by measuring allergen-specific igg as an objective parameter. immunotherapy-myths, reality, ideas, future. London: InTech; 2017.

Thanh VH, Okubo K, Shibasaki K. Isolation and characterization of the multiple 75 globulins of soybean proteins. Plant Physiology 1975;56(1):19-22.

Wang T, Qin GX, Sun ZW, Zhao Y. Advances of research on glycinin and $\beta$-conglycinin: a review of two major soybean allergenic proteins. Critical Reviews in Food Science and Nutrition 2014;54(7):850-862.

Wu C, Hua $Y$, Chen $Y$, Kong $X$, Zhang C. Microstructure and model solute transport properties of transglutaminase-induced soya protein gels: effect of enzyme dosage, protein composition and solute size. International Journal of Food Science \& Technology 2017:52:15271533.

Wu JJ, Cao CM, Meng TT, Zhang Y, Xu SL, Feng SB, et al. Induction of immune responses and allergic reactions in piglets by injecting glycinin. Italian Journal of Animal Science 2016;15(1):166-173.
Xu J, Zhou A, Wang Z, Ai D. Effects of glycinin and B-conglycinin on integrity and immune responses of mouse intestinal epithelial cells. Journal of Animal and Plant Sciences 2010;20(3):170-174

Yamada T, Mori Y, Yasue K, Maruyama N, Kitamura K, Abe J. Knockdown of the $7 \mathrm{~S}$ globulin subunits shifts distribution of nitrogen sources to the residual protein fraction in transgenic soybean seeds. Plant Cell Reports 2014;33(12):1963-1976.

Yi D, Hou Y, Mei H, Wang L, Hu C-AA, Wu G.ß-Conglycinin enhances autophagy in porcine enterocytes. Amino Acids 2017;49(1):203-207.

Zhang JX, Guo LY, Feng L, Jiang WD, Kuang SY, et al. Soybean $\beta$-conglycinin induces inflammation and oxidation and causes dysfunction of intestinal digestion and absorption in fish. Plos One 2013;8(3):e58115.

Zhao Y, Qin G, Sun Z, Zhang X, Bao N, Wang T, et al. Disappearance of immunoreactive glycinin and $\beta$-conglycinin in the digestive tract of piglets. Archives of Animal Nutrition 2008;62(4):322-330. 